Original Article

\title{
EXPLORING PHARMACY STUDENTS' KNOWLEDGE AND UNDERSTANDING OF EATING DISORDERS AND THEIR IMPACT ON MENTAL HEALTH AND QUALITY OF LIFE
}

\author{
AQSA MAHMOOD, PATRICK BALL, HANA MORRISSEY
}

The University of Wolverhampton, United Kingdom

Email: hana.morrissey@wlv.ac.uk

Received: 06 May 2021, Revised and Accepted: 03 Jul 2021

\begin{abstract}
Objective: Eating disorders are a group of mental illnesses that are long-term and potentially life-threatening, affecting individuals' physical and emotional health and wellbeing. They commonly exist alongside other mental health conditions such as depression and anxiety and are associated with a significant reduction in an individual's quality of life and life expectancy. They are poorly understood, and cases may be undiagnosed and thus untreated. This can result in damage to multiple organs, including the brain, heart, and kidneys.
\end{abstract}

Methods: This was an online questionnaire-based study, which consisted of 21 open and closed-ended questions. Participants were from years 1 to 4 of the MPharm course at the University of Wolverhampton.

Results: Fourty two completed surveys were returned. The results of the study revealed that pharmacy students lacked knowledge of eating disorders, which was also illustrated in previously conducted studies amongst other healthcare professions students. Therefore, it is evident that the current education about eating disorders is insufficient in many undergraduate healthcare courses and there is room for improvement.

Conclusion: Improving future pharmacist's knowledge about eating disorders would assist better and earlier identification of patients with such conditions, allowing timely support.

Keywords: Eating disorders, Pharmacy students, Community pharmacist, Depression, Anxiety

(c) 2021 The Authors. Published by Innovare Academic Sciences Pvt Ltd. This is an open-access article under the CC BY license (https://creativecommons.org/licenses/by/4.0/) DOI: https://dx.doi.org/10.22159/ijcpr.2021v13i5.1895 Journal homepage: https://innovareacademics.in/journals/index.php/ijcpr

\section{INTRODUCTION}

Eating disorders are complicated mental health conditions involving patterns of unusual eating habits, including; anorexia nervosa, bulimia nervosa and binge eating [1]. Other types can include pica, avoidant or restrictive food intake disorder (ARFID) due to textures, colors, or temperature, and rumination disorder [2, 3].

Eating disorders may develop at any age but are commonly present during adolescence and early adulthood, affecting more females than males [4]. Reportedly, up to $13 \%$ of youngsters go through a minimum of one eating disorder by the time they reach the age of 20 [2]. The UK eating disorder charity, BEAT, (2017) estimated that approximately 1.25 million people in the UK are affected by an eating disorder, with $25 \%$ of this population being male. $6.4 \%$ of adults in England in 2007, were positively screened for a potential eating disorder, which resulted in a severe reduction in quality of life, with damage escalating with the severity of the disease $[5,6]$.

It is believed that eating disorders occur due to a combination of several different factors, which can include biological, genetic, psychological, social or cultural [7]. Social pressures promoting the 'trend of thinness' through magazines and television with advice on weight reduction, diets, and the fashion industry, have been quoted as a crucial reason behind the increased incidence of eating disorders and its higher occurrence in females [8]. The portrayal of messages and images focusing on the significance of appearances and slimness can result in major undesirable influences on body satisfaction, weight concern, patterns of eating, and the emotional health of women [9]. Martin (2010) determined that $69 \%$ of American females attending elementary school had been influenced by images presented within magazines and their perception of ideal body shape, with $47 \%$ of these individuals stating the pictures encouraged weight loss [10]. Around $40 \%$ of females and $37 \%$ of males who were overweight had been harassed of their weight by peers or members of the family [11], potentially resulting in weight gain, binge eating, and severe measures for weight control.
Early diagnosis and treatment of eating disorders can improve outcomes, and the associated complications reversed or improved with timely and appropriate treatment; therefore, assessment and intervention should ideally occur at an early stage, particularly for those at risk of major emaciation, with such individuals being prioritised for treatment [12]. Psychotherapy or counselling are long-lasting and the most effective treatments for an eating disorder, together with attention to medical and nutritional requirements. Preferably, the treatment offered should be tailored to the individual patient and will differ depending on the individual problems and needs and the type and severity of the disorder. Nonetheless, the treatment should address the symptoms of the eating disorder and the associated psychological, biological, medical, interpersonal and cultural complications that have a role in or influence the eating disorder [13].

Studies regarding eating disorders have noted a significant reduction in quality of life, to the extent that is comparable with those in a number of other major conditions, including anxiety and angina [14]. Additionally, negative influences on relationships, fertility, academic performance, employment and parenting may occur and become persistent, even after recovery [12]. Eating disorders can cause deterioration of personal health and frequently coexist with depression, anxiety, substance misuse and other mental health disorders [15, 16]. In 2017, globally, approximately 792 million individuals suffered from a mental health disorder, roughly 1 in 10 people, or $10.7 \%$ of the population [17]. Chesney, Goodwin and Fazel (2014) concluded that mental health disorders can reduce life span by ten to twelve years, which is greater than the reduction in life span anticipated in those who smoke more than 20 cigarettes per day [18]. Major depression was identified as the most frequently seen psychiatric disorder in anorexic females, and this was also common in bulimia nervosa [19]. It was illustrated that $77 \%$ of individuals suffering from an eating disorder had a lifetime diagnosis of Diagnostic and Statistical Manual of Mental Disorders (DSM) major affective disorder, as well as high rates of anxiety disorders, substance use disorders, and kleptomania [20]. Though some individuals who receive treatment have reasonable outcomes, those with poor 
treatment outcomes are at an elevated risk for physical illness, psychiatric disorder, suicide attempts, and mortality [21].

Studies have acknowledged eating disorders as having the highest rate of mortality of all mental health conditions [22]. They can be accompanied with suicidal ideation, and suicide is known to be a major cause of death in these individuals [23]. The increased risk of suicide in those with bulimia was identified to be comparable to anorexia; however, anorexia nervosa presents with the highest rates of completed suicide of all eating disorders [24]. There was a six-fold increase in the risk of mortality in comparison to the general population, with causes of death being starvation, substance abuse, and suicide [13]. In individuals struggling with binge eating disorder, approximately half attempted suicide [23].

One study researched into the impact of body image on quality of life and provided participants numerous questionnaires, including the Body Image and Quality of Life Inventory-Spanish version (BIQLI-SP) and SelfEsteem Scale (SES), which measured the impact of body image in multiple areas of psychosocial functioning i.e. interaction with others. Their results demonstrated that their influence of body image on the quality of life produced the greatest impact within the eating disorder group, which consisted of 70 patients [25]. The results from this study were consistent with the study carried out by de la Rie, Noordenbos and van Furth (2005), who reported that eating disorders result in major implications on numerous aspects of quality of life [26]. Additionally, it was concluded by studies that those with a negative body image were more prone to dieting, avoiding meals, avoiding socialization, and developing an eating disorder [27]).

Ruffolo et al. (2005) concluded that subjects with eating disorders (9.0\% with anorexia nervosa, $6.5 \%$ with bulimia nervosa, and $17.5 \%$ with an eating disorder not otherwise specified) had considerably greater disturbances in body image, as well as having received further treatment for other mental health issues [28]. Another study found that individuals with binge-eating disorders were obese, which may have played a role in developing the condition [29]. Studies regarding the misuse of laxatives amongst individuals identified prevalence fig. varying from $2 \%$ in students at secondary schools to $12.8 \%$ in college students, with considerably increased rates in the eating disorder populations [30]. In anorexic individuals, the frequency of laxative use was reported to be $32 \%$ [31] and 75\% in bulimic individuals [32]. The misuse of laxatives can result in a number of severe consequences, including dysfunction of the gastrointestinal tract, kidney disease, severe dehydration, electrolyte imbalance can result in cardiac arrest $[33,34]$. Identifying and offering support to individuals who misuse laxatives is an important role of community pharmacists. A letter sent to the Royal Pharmaceutical Society from an individual with an eating disorder stated, "Yesterday I was once again discharged from hospital after excessively abusing laxatives for the past three years. I have been taking these tablets to the excess of 100 a day. This was not usually a problem, as many chemists would sell them to me repeatedly every day... Last year I weighed four stone and looked near death, and very rarely did a pharmacist question me. I got to know the chemists that would feed my habit without hesitance and became confident about purchasing tablets from them...", this was a person calling for action in order to stop the general sales of laxatives [30]. Discussing eating disorders with patients and their parents can be distressing and challenging. Pharmacists are typically the first healthcare professional with whom most people come into contact. Therefore, pharmacist's knowledge about eating disorders, its association with other mental health disorders and the impact of this on quality of life, is essential for early identification and referral for further investigations to prevent severe consequences [35].

\section{Aim}

The aim of this research project was to investigate pharmacy students' knowledge and understanding of eating disorders and body image and the impacts of this on mental health and quality of life.

\section{The objectives of this research project were:}

1. To identify the level of knowledge and understanding about eating disorders within pharmacy students.
2. To determine future pharmacists understanding about the impact of body and self-image on mental health.

3. To help raise awareness of eating disorders amongst pharmacy students.

\section{MATERIALS AND METHODS}

\section{Methods and design}

A questionnaire-based study was carried out in the 'Black Country' area in the English Midlands. A link was sent to undergraduate pharmacy students, inviting them to complete a questionnaire regarding eating disorders. The questionnaire was specifically produced and targeted for this population due to the fact that they would be future pharmacists thus potentially be the first point of contact for patients about this issue. Alternative study designs such as interviews or focus groups were not possible due to COVID-19 pandemic and associated lockdowns.

The questionnaire was produced in a Microsoft $\AA$ MS-word ${ }^{\mathrm{TM}}$ document with the help of multiple websites such as BEAT eating disorders and already known topics regarding eating disorders to come up with questions. The 21 questions were produced and finalised including both open and closed questions. It was anticipated that the completion of the questionnaire would take participants approximately $20 \mathrm{~min}$. Due to the COVID-19 pandemic at the time of data collection, face-to-face distribution of questionnaires was not possible and therefore, to allow adequate distribution of the questionnaire, Online Surveys ${ }^{\circledR}$ was used. The participant information sheet was included in the introductory page, which was shown when participants first clicked onto the survey link. The questionnaire was then published and the link was sent to all fourth-year pharmacy students inviting them to participate. The survey was open for a period of two months. Consent was implied by students completing and submitting the questionnaire. Microsoft $®$ Excel $^{\mathrm{TM}}$ was used for data analysis.

\section{Ethics}

Ethical approval was granted on the $4^{\text {th }}$ of November 2020 by the University of Wolverhampton, School of Pharmacy Ethics Committee.

\section{Sample/data source/data analysis}

The target group was fourth-year undergraduate students who had completed all the therapeutics and pharmacy practice foundation topics in the previous three years of the course. Out of 65 students enrolled in the fourth year, $42(66 \%)$ took part. The study was inclusive of all genders, ages (above $18 \mathrm{y}$ of age) and ethnicities.

Individuals who decided voluntarily to take part, completed the 21 questions surrounding the topic of eating disorders. The responses were downloaded from the online survey tool into a Microsoft Excel® spreadsheet for analysis.

\section{RESULTS}

The response rate was higher than most online surveys (30\%), with $66 \%(n=42)$ of the student cohort taking part. In total, 42 questionnaires had been completed and submitted over the time the survey was open. Questions 1, 2, and 3 focused on collecting demographic data. There were $85 \%$ of participants in $18-25$ age group, $5 \%$ in $26-30$ age group and $10 \%$ in $31-35$ age group. There $71 \%$ females and $29 \%$ males. This is similar to the gender balance in the UK today, with GPhC data from 2017 showing more female pharmacists (62\%) than male pharmacists $(39 \%)$ [36]. Examining self-identified ethnicity, $63 \%$ of the participants were from Asian, $12 \%$ were black, $5 \%$ were Arabic, $12 \%$ were white and $8 \%$ from other backgrounds.

Question 4 was formulated to ask students whether they themselves had struggled with an eating disorder, with $14.6 \%$ of participants reporting to have the first-hand experience of an eating disorder. Those who said they had suffered from an eating disorder were all females $(100 \%)$ and from the Asian background except for 1 participant who was Black. In the UK, the population of people that experience an eating disorder is made up of $75 \%$ of females [5]. These participants were $<25 \mathrm{y}$ of age. 
Questions 5 and 6 asked participants about their thoughts on the age and gender most commonly affected by eating disorders with $88 \%$ of participants selected the female gender. Most people (58\%) thought that the condition most commonly affected those aged 18 or under (fig. 1).

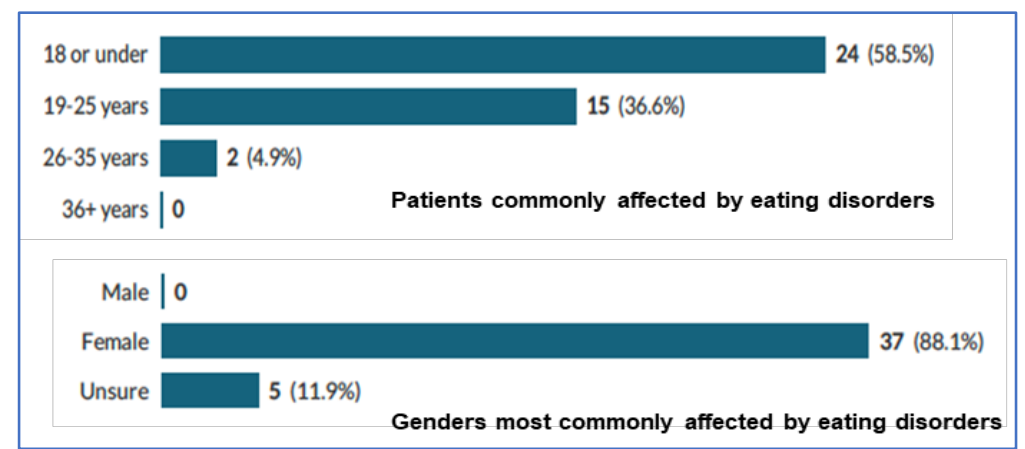

Fig. 1: Pharmacy students' thoughts on the age and gender of patients commonly affected by eating disorders

Questions 7 and 8 looked into whether pharmacy students were aware of the most common type of eating disorder and whether they were mindful of the impact that eating disorders could have on the quality of life. The most popular answer was binge eating disorder
(43\%), followed by anorexia (33\%), and finally, bulimia (24\%). All pharmacy students had stated eating disorders had a serious impact on the quality of life. Those who chose binge eating as being the most common type of eating disorder were all females (fig. 2).

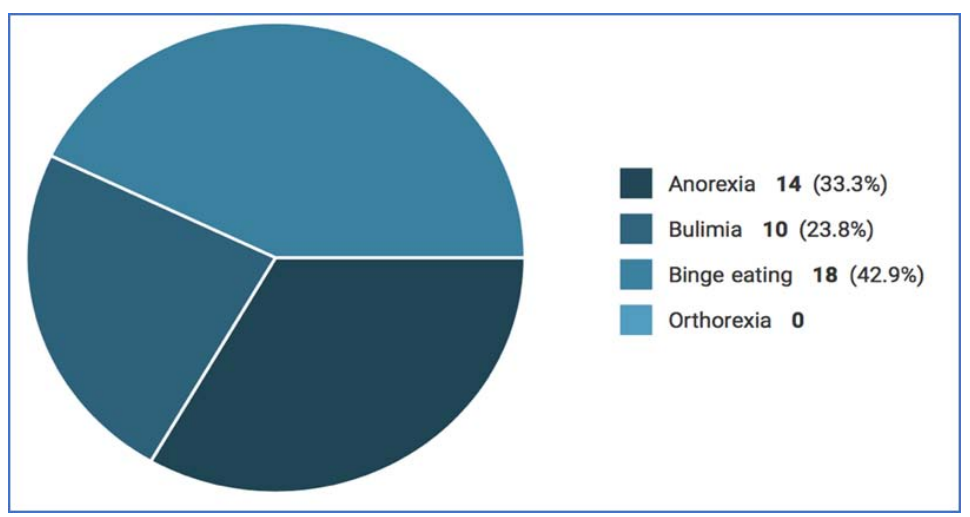

Fig. 2: Responses for the most common type of eating disorder

The next 3 questions $(9,10$, and 11) were designed to determine whether participants were knowledgeable and able to differentiate between eating disorder symptoms of the three most common types of eating disorders (fig. 6-8).

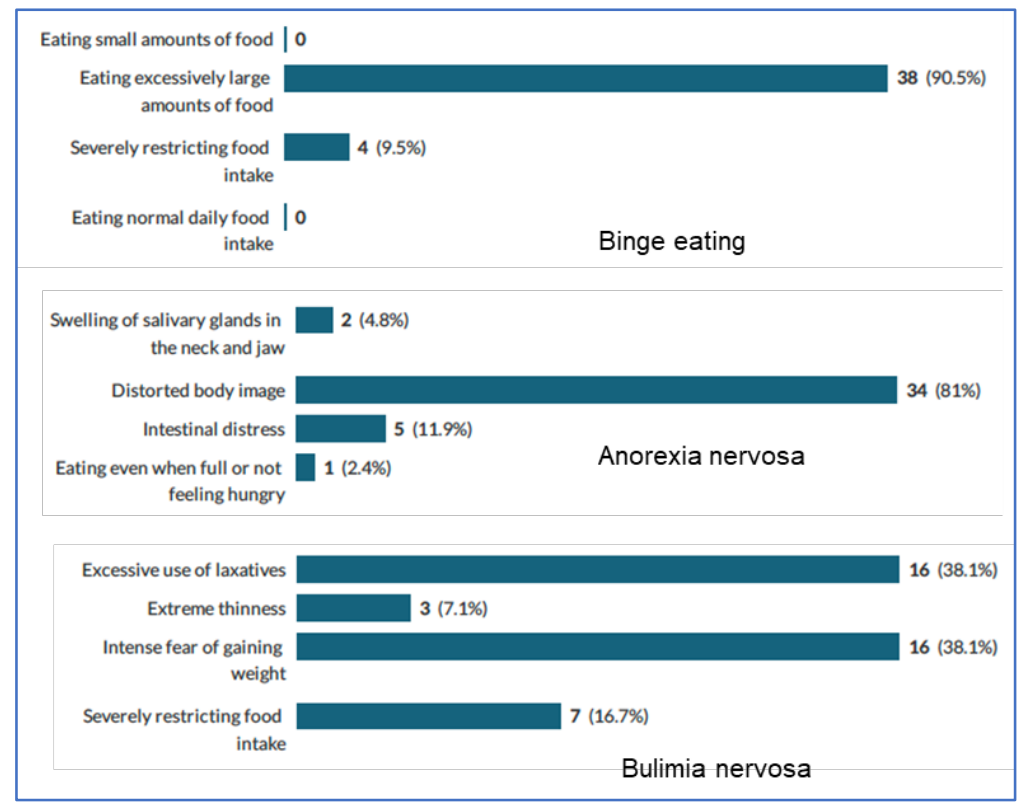

Fig. 3: Understanding the different disorders signs and symptoms 
Question 12 was produced to ask pharmacy students whether being of a normal weight meant patients didn't suffer from eating disorders, $90 \%$ of participants said eating disorders could occur in those of normal weight (fig. 4).

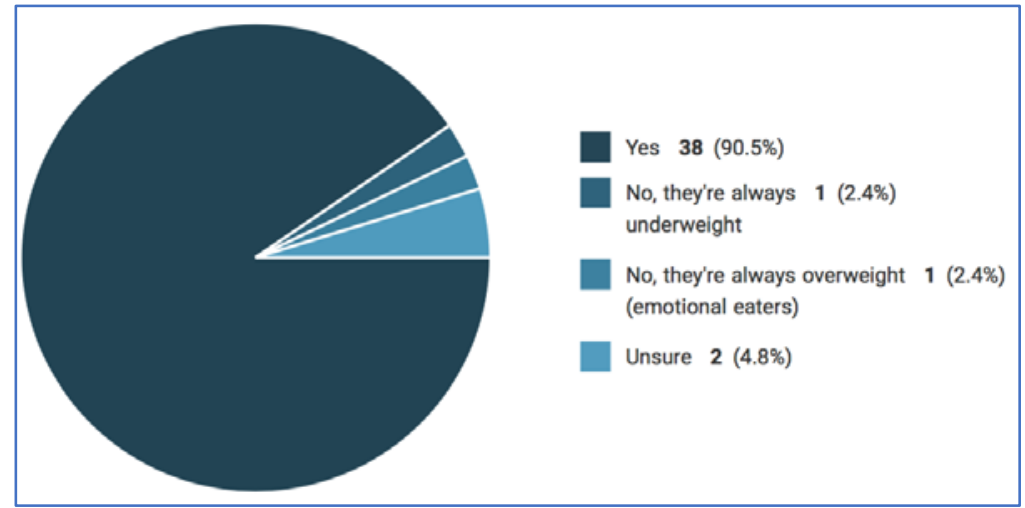

Fig. 4: Pharmacy students' thoughts on whether eating disorders can affect individuals of normal weight

Students in question 13 were asked to identify the comorbidities known to be associated with eating disorders. While a large (83\%) number of participants correctly identified all given options as comorbidities (depression, anxiety, self-harm, and personality order), the remainder of participants selected only one option.

Question 14 asked participants to list long-term consequences that could be a result of eating disorders. A variety of different answers had been obtained, some of which included infertility, irregular periods, dental problems, diabetes, cardiovascular diseases, and even death. Students were then asked to identify the most effective treatment for bulimia nervosa, with $71 \%$ of participants correctly identifying cognitive-behavioral therapy (CBT) as being the most effective treatment option. This was followed by counseling (60\%), then antidepressant therapy (17\%) and antipsychotics (7\%). The next question asked pharmacy students whether they thought eating disorders had an impact on the way an individual interacts with others; $83 \%$ of participants agreed. Additionally, $97.4 \%$ of respondents said that social media and magazines can have an influence in the development of anorexia (fig. 5).

Questions 18 and 19 were intended to determine whether participants were aware about the long-term and short-term implications of bulimia nervosa and binge eating disorders (fig. 6).

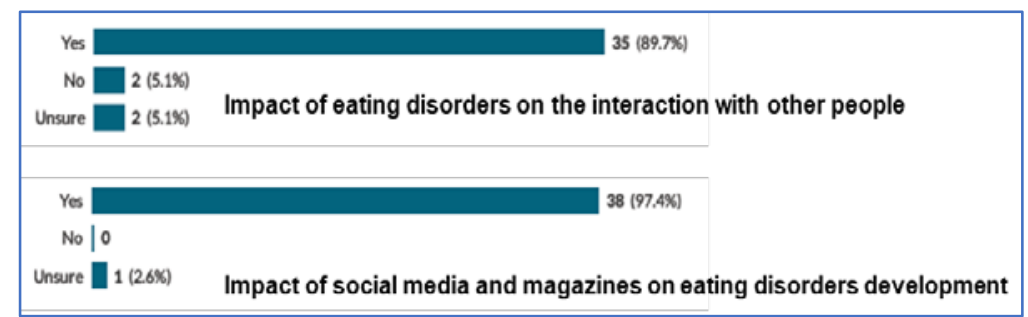

Fig. 5: Eating disorders consequences and triggers

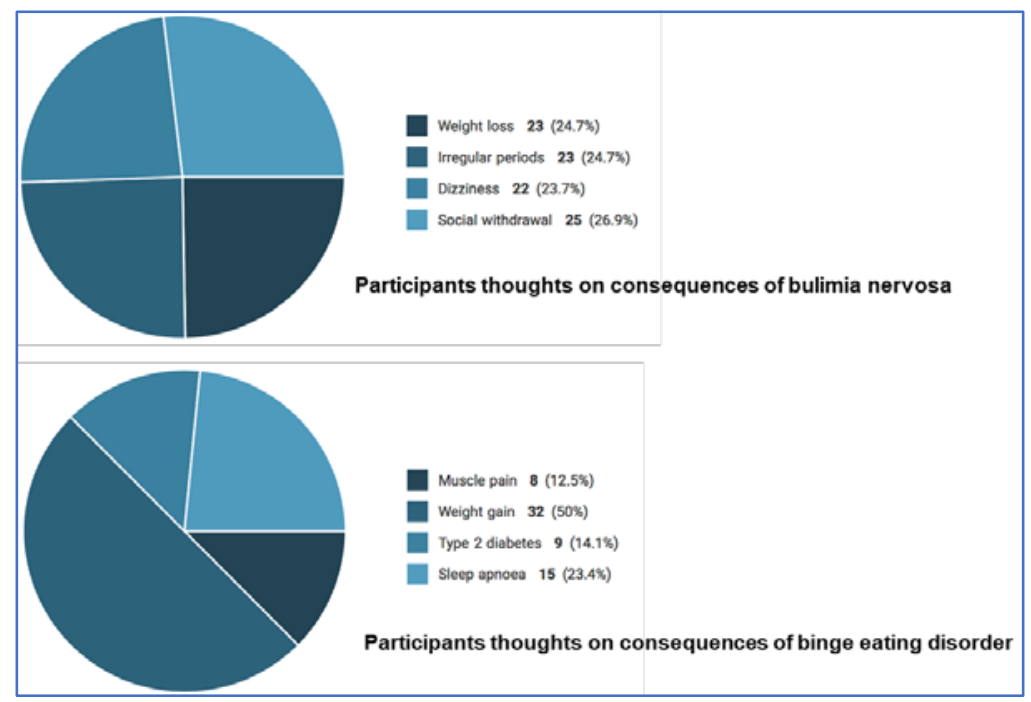

Fig. 6: Participants free text thoughts 
The next question asked pharmacy students what the impact of the COVID-19 pandemic had been on those suffering from an eating disorder. Most participants (71.4\%) stated that the pandemic had caused bulimic individuals to binge (fig. 7).

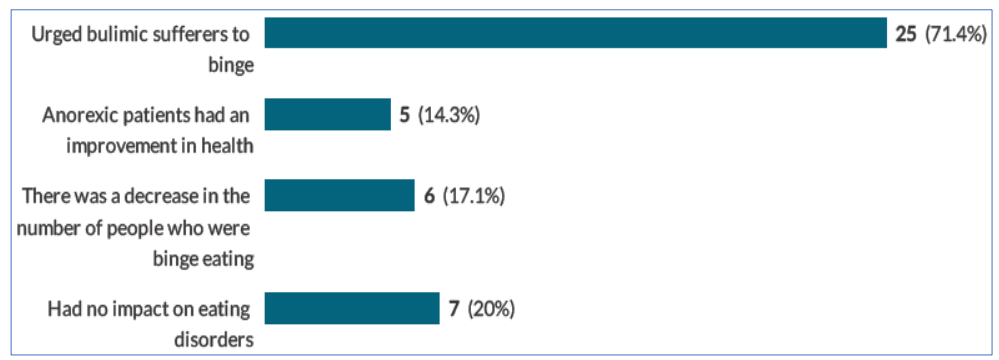

Fig. 7: Responses to thoughts on the impact of COVID-19 on eating disorder patients

\section{DISCUSSION}

Table 1 summarises the correct and incorrect answers for questions 5-20. This was important to understand the students' level of correct knowledge.

Table 1: Summary of knowledge level test

\begin{tabular}{lll}
\hline Question & Correct answer & Incorrect answer \\
\hline 5 & $93 \%(n=39)$ & $5 \%(n=2)$ \\
6 & $88 \%(n=37)$ & $0 \%(n=0)$ \\
7 & $43 \%(n=18)$ & $57 \%(n=24)$ \\
8 & $100 \%(n=42)$ & $0 \%(n=0)$ \\
9 & $90 \%(n=38)$ & $10 \%(n=4)$ \\
10 & $81 \%(n=34)$ & $19 \%(n=8)$ \\
11 & $40 \%(n=17)$ & $60 \%(n=25)$ \\
12 & $90 \%(n=38)$ & $5 \%(n=2)$ \\
13 & $83 \%(n=35)$ & $17 \%(n=7)$ \\
15 & $71 \%(n=30)$ & $21 \%(n=9)$ \\
16 & $83 \%(n=35)$ & $5 \%(n=2)$ \\
17 & $90 \%(n=38)$ & $0 \%(n=0)$ \\
18 & $55 \%(n=23)$ & $36 \%(n=15)$ \\
19 & $76 \%(n=32)$ & $14 \%(n=6)$ \\
20 & $60 \%(n=25)$ & $24 \%(n=10)$ \\
\hline
\end{tabular}

Eating disorders is more common in females and young people in general [4] and approximately $13 \%$ of young people undergo a minimum of one eating disorder by the time they reach the age of 20 [2]. It is estimated that out of the 700,000 people with eating disorders in the UK, females make up $90 \%$ of this population [37]. All participants $(n=6)$ who disclosed that they had personally experienced an eating disorder in this study were females.

Of those who selected binge eating as one of the most common types of eating disorders, $73 \%$ were females, and all females and males were from Asian backgrounds. The correct option for question 10 was 'Distorted body image', which was determined by $81 \%$ of the pharmacy students $(25 \%$ males and $75 \%$ females), all from the Asian background. For the option 'excessive use of laxatives' $60 \%$ of participants selected as the correct answer, as a sign of possible bulimia, were from the Asian background. The vast majority (90\%) had stated that individuals of normal weight could also be sufferers of eating disorders; this is similar to the findings of Haelle (2014) that individuals did not have to look extremely thin to be following dangerous trends in eating behaviours, in fact, an extreme drop in weight was shown to carry the same risk for life-threatening problems even if the individual was of normal weight [38].

Regarding eating disorder comorbidities; $17 \%$ of the participants had failed to identify that all given options were in fact common comorbidities associated with eating disorders (all were from Asian background).

When asked about the most effective treatment for eating disorders, participants had the ability to select more than one given option,
$21 \%$ failed to choose CBT as being the most effective treatment (67\% of females) as recommended by NICE (2017). While $83 \%$ of individuals were aware of the fact that eating disorders actually affected an individual's interaction with other people, the remainder (Asian, females) did not realise that interaction between an eating disorder patient and other individuals is significantly impaired. The majority $(90 \%)$ of the participants agreed that social media and magazines having an influence on the development of anorexia nervosa. Magazines and social media can advise on weight reduction, diets, and fashion trends, and have been quoted as a crucial reason behind the increased incidence of eating disorders [8]. Participants were then given the freedom of selecting more than one option to list of long-and short-term implications of eating disorders (questions 18 and 19). These two questions were poorly answered (table 1) which indicates that the topic could be better taught and highlighted in the course therapeutics topics.

With the situation of the COVID-19 pandemic, it was appropriate to formulate a question that would ask pharmacy students about the impact the pandemic had on those suffering from an eating disorder. Most participants had correctly stated that the COVID-19 pandemic had negatively impacted on those affected with an eating disorder and had caused many individuals to binge eat.

\section{Open-end questions and comments}

Only three participants commented on the long-term impact of eating disorders and classified then as physical, mental and social implications. The majority of the participants commented on the physical impact of eating disorders as being infertility, irregular periods, dental problems, and malnourishment. Menstrual cycle disruption can be a result of the reduction in the levels of oestrogen due to restriction of calorie intake or excessive exercise, and with an increase in the prevalence of menstrual disruptions, infertility can occur [39]. A few participants had also stated diabetes, weight gain and weight loss as potential consequences of eating disorders. Binge eating disorder is one of the commonest conditions that can be associated with obesity, which occurs as a result of continuous weight gain over the long-term course of the condition [40]. Eating disorders are mental health conditions that commonly have a comorbidity of other mental health disorders. Participants identified depression and anxiety as potentially comorbid conditions with eating disorders which agrees with the National Eating Disorders Collaboration (2021) statement, which also included substance use disorders, sexual dysfunction, post-traumatic stress disorder (PTSD), and self-harm and suicidal ideation [41]. The majority of the participants stated that low self-esteem, low quality of life and a disparaging view of oneself, had serious impacts on views of life, body image, reduction in social confidence, social withdrawal, including from relationships, friends and family, and self-doubt as possible social effects that could occur as a result of eating disorders.

One of the responses received from pharmacy students was death (by suicide) as a long-term implication of disordered eating. The rate of suicide for those affected with bulimia nervosa was 7.5 times higher than individuals of the general public [41]. 
The final question was intended to provide participants with the opportunity to express their thoughts and perceptions on the attitude of pharmacists towards patients with eating disorders. Out of the 42 participants that had taken part in this questionnaire, $69 \%$ had left a response to this question and out of those that had responded.

Regarding 'Pharmacists are compassionate to those with eating disorders' statement, participants thought that:

"Pharmacists can help as much as they can, but more awareness should be given".

"Pharmacists do sympathise towards people who have eating disorders".

"Pharmacists should be sympathetic towards patients with suspected eating disorders and as a healthcare professional have a role/duty to support and advise the patient on ways to get help and improve their health".

"Pharmacists can be beneficial in counselling provided they take the appropriate courses to equip them with these skills".

Pharmacists should be knowledgeable about the possibility for altered pharmacokinetics in individuals with eating disorders, which could occur as a result of starvation, dehydration, and vomiting which may require lower doses of medications to be used [42]. Regarding 'Pharmacists require more knowledge' statement, participants thought that:

"Pharmacists do not know a lot about eating disorders and how to manage them".

"They may not be aware of it".

"Not doing enough, nothing for them to do".

"Pharmacists aren't really educated enough on the topic of eating disorders but should be".

"I think generally more knowledge is needed to understand those with eating disorders more".

It is believed that pharmacists can in fact play a part in the monitoring of electrolytes, in particular during the early stages of reseeding as well as providing advice on pharmacological treatments for associated comorbidities [42]. Regarding 'More recognition is needed amongst pharmacy students' statement, participants thought that:

"It is not a condition that can be directly impacted by pharmacological intervention".

Individuals with disordered eating were looked at differently by nursing and medical professionals and were "seen as responsible for their illness" [43]. This demonstrates greater negativity towards these specific individuals compared to other patient groups, suggesting the condition is not perceived to be as severe as other mental health disorders, which could reflect limited knowledge. This may compromise medical services for affected patients, and therefore it has been concluded that students could benefit from additional knowledge and teaching of eating disorders, as research has shown it to be a commonly ignored condition amongst healthcare professionals. As eating disorders have a high rate of mortality compared to all other mental health conditions (Herzog, 2000), the awareness raised within pharmacy students and thus an increased chance of the involvement of pharmacists, could offer potential for reducing the suicide rate, which is the most common result of death amongst these individuals [23].

\section{LIMITATIONS}

The majority of this fourth-year cohort were females and from Asian or Black heritage, which limits the generalisation of the results.

\section{CONCLUSION}

This study aimed to explore pharmacy student's knowledge and understanding of eating disorders and its implicaitons on quality of life and development of additional mental health disorders, through a questionnaire-based approach. The study question, aim and objectives were successfully met. Whilst the responses varied depending on the depth of the tested knowledge, there were a number of participants who demonstrated adequate knowledge of the topic investigated. Nevertheless, based on the qualitative and quantative analysis of results, it was clear that current pharmacy students lack knowledge of these commonly overlooked conditions and could benefit from additional learning exposure on eating disorders and mental health disorders. Areas for further research can include placing the focus of research solely onto eating disorder subjects to investigate their perception on pharmacists' involvement regarding this particular condition.

Eating disorders are a common mental health issue affecting teenagers and young adults, which is an age where these groups of individuals will be aiming to achieve qualifications, planning and starting their careers and making important life choices. If their mental health is impaired due to the diagnosis of an eating disorder, it would limit their achievements and possibly have major implications on their life decisions. Pharmacists can have an essential role in the identification of eating disorders by being aware of common eating disorder symptoms as well as the most common non-prescription and prescription items and medications misued by these individuals.

\section{ACKNOWLEDGMENT}

$\mathrm{N} / \mathrm{A}$

\section{FUNDING}

\section{No external funding}

\section{AUTHORS CONTRIBUTIONS}

AM: Concept and design of study, acquisition of data, analysis and interpretation of data; HM: Supervised the concept and design of study development, analysis and interpretation of data, drafting the article and approval of the version to be published; BP: Critically review of the article and the version to be published

\section{CONFLICT OF INTERESTS}

No conflicts of interest to declare

\section{REFERENCES}

1. Lask B, Waugh RB. Anorexia nervosa and related eating disorders in childhood and adolescence. London: Psychology Press; 2000.

2. Petre A. 6 Common types of eating disorders (and Their Symptoms); 2019. Available from: https://www. healthline.com/nutrition/common-eating-disorders. [Last accessed on 17 Nov 2020]

3. Talley NJ. Rumination syndrome. Gastroenterol Hepatol 2011;7:117-8.

4. World Health Organisation. Adolescent mental health; 2020. Available from: https://www.who.int/news-room/factsheets/detail/adolescent-mental-health. [Last accessed on 17 Nov 2020]

5. BEAT. Types of eating disorder; 2017. Available from: https://www.beateatingdisorders.org.uk/types. [Last accessed on 17 Nov 2020]

6. Bebbington P, Brugha T, Coid J, Crawford M, Deverill C, D’Souza J, et al. Adult psychiatric morbidity in England; 2009. Available from: https://webarchive.nationalarchives.gov.uk/20130104162040/ht tps:/catalogue.ic.nhs.uk/publications/mental-

health/surveys/adul-psyc-morb-res-hou-sur-eng-2007/adul-psycmorb-res-hou-sur-eng-2007-rep.pdf. [Last accessed on 17 Nov 2020].

7. Your Health in Mind. Eating disorders; 2015. Available from: https://www.yourhealthinmind.org/mental-illnessesdisorders/eating-disorders. [Last accessed on 17 Nov 2020]

8. World Health Organisation. Gender in mental health research; 2005. Available from: https://www.who.int/gender/ documents/MentalHealthlast2.pdf. [Last accessed on 17 Nov 2020].

9. Spettigue W, Henderson KA. Eating disorders and the role of the media. Can Child Adolesc Psychiatr Rev 2004;13:16-9.

10. Martin JB. The development of ideal body image perceptions in the united states. Nutr Today 2010;45:98-100.

11. Golden NH, Schneider M, Wood C. Preventing obesity and eating disorders in adolescents. Pediatrics 2016;138:e20161649. 
12. NICE. Eating disorders: recognition and treatment; 2017. Available from: https://www.nice.org.uk/guidance/ ng69/ chapter/Recommendations\#identification-and-assessment. [Last accessed on 17 Nov 2020]

13. Mental Health America. Eating disorders; 2020. Available from: https://www.mhanational.org/conditions/eating-disorders. [Last accessed on 20 Nov 2020]

14. DeJong $H$, Oldershaw A, Sternheim L, Samarawickrema N Kenyon MD, Broadbent $\mathrm{H}$, et al. Quality of life in anorexia nervosa, bulimia nervosa and eating disorder not-otherwisespecified. J Eating Disorders 2013;1:43.

15. Hughes E, Goldschmidt AB, Labuschagne Z. Eating disorders with and without co-morbid depression and anxiety: Similarities and differences in a clinical sample of children and adolescents. Euro Eating Disorders Rev 2013;21:386-94.

16. Araujo DM, Santos GF, Nardi AE. Binge eating disorder and depression: a systematic review. World J Biol Psychiatry 2010;11:199-207.

17. Ritchie H, Roser M. Mental health; 2018. Available from: https://ourworldindata.org/mental-health\#citation. [Last accessed on 18 Dec 2020].

18. Chesney E, Goodwin GM, Fazel S. Risks of all-cause and suicide mortality in mental disorders: a meta-review. World Psychiatry 2014;13:152-60.

19. Fairburn C, Brownell KD. Eating disorders and obesity. New York: The Guilford Press; 2002.

20. Hudson JI, Pope HG, Jonas JM, Yurgelun Todd D. Phenomenologic relationship of eating disorders to major affective disorder. Psychiatry Res 2002;9:345-54.

21. Johnson JG, Cohen P, Kasen S. Eating disorders during adolescence and the risk for physical and mental disorders during early adulthood. Arch Gen Psychiatry 2002;59:545-52.

22. Herzog DB, Greenwood DN, Dorer DJ, Flores AT, Ekeblad ER, Richards A, et al. Mortality in eating disorders: a descriptive study. Int J Eat Disord 2000;28:20-6.

23. Ekern J. Eating disorders and suicide; 2019. Available from https://www.eatingdisorderhope.com/treatment-for-eatingdisorders/eating-disorders-and-suicide. [Last accessed on 20 Nov 2020]

24. Guillaume S, Jaussent I, Olie E, Genty C, Bringer J, Courtet P, et al. Characteristics of suicide attempts in anorexia and bulimia nervosa: a case-control study. PLoS One 2011;6:e23578.

25. Lobera IJ, Rios PB. Body image quality of life in eating disorders. Patient Prefer Adherence 2011;5:109-16.

26. de la Rie SM, Noordenbos G, van Furth EF. Quality of life and eating disorders. Qual Life Res 2005;14:1511-22.

27. Levine MP, Smolak L. Annual review of eating disorders: prevention of negative body image, disordered eating, and eating disorders. London: CRC Press; 2018.

28. Ruffolo JS, Phillips KA, Menard W, Fay C, Weisberg RB. Comorbidity of body dysmorphic disorder and eating disorders: severity of psychopathology and body image disturbance. Int J Eating Disorders 2005;39:11-9.

29. Rieger E, Wilfley DE, Stein RI, Marino V, Crow SJ. A comparison of quality of life in obese individuals with and without binge eating disorder. Int J Eating Disorders 2005;37:234-40.
30. Bryant Waugh R, Turner H, East P. Over-the-counter laxatives and eating disorders-a survey of pharmacists' and other retailers' views and practise. Pharm J 2005;275:87-91.

31. Turner J, Batik M, Palmer LJ, Forbes D, McDermott BM. Detection and importance of laxative use in adolescents with anorexia nervosa. J Am Academy Child Adolescent Psychiatry 2000;39:378-85.

32. Abraham SF, Beumont PJV. How patients describe bulimia and binge-eating. Psychol Med 1982;12:625-35.

33. Brunton J. Laxative abuse in eating disorders; 2017. Available from: https://www.rcpsych.ac.uk/docs/defaultsource/members/faculties/eating-disorders/laxative-abusein-eating-disorders-ed-faculty-resp.pdf?sfvrsn=6605a8ef_2. [Last accessed on 11 Dec 2020]

34. NEDA Feeding hope. Laxative Abuse; 2018. Available from: https://www.nationaleatingdisorders.org/learn/generalinformation/laxative-abuse. [Last accessed on 10 Dec 2020]

35. National Eating Disorders Collaboration Pharmacy and Eating Disorders; 2020.2 Available from: https://www.nedc.com.au/assets/NEDC-Resources/NEDCResource-Pharmacists.pdf. [Last accessed on 08 Dec 2020]

36. Anekwe L. Gender inequality higher at senior level of pharmacy bodies and chains; 2018. Available from: https://www.chemistanddruggist.co.uk/news/genderinequality-higher-senior-level-pharmacy-bodies-and-chains. [Last accessed on 13 Jan 2021]

37. NICE Eating disorders: How common is it?; 2019. Available from: https://cks.nice.org.uk/topics/eating-disorders/ background-information/prevalence/ \#: :text= Lifetime $\% 20$ eating $\% 2$ disorders $\% 20$ to $\% 20$ be $\% 208.4 \% 25 \% 2$ 0(range\%203.3-18.6\%25),\%5BZipfel,\%202015;\%20KeskiRahkonen,\%202016;\%20NICE,\%202017;\%20Berends,\%2020 18\%5D. [Last accessed on 31 Jan 2020]

38. Haelle T. Normal-weight teens can have eating disorders; 2014. Available from: https://www.webmd.com/mentalhealth/eating-disorders/news/20140826/even-normalweight-teens-can-have-dangerous-eating-disorders-studyfinds\#1. [Last accessed on 16 Jan 2021]

39. Hoffman ER, Zerwas SC, Bulik MC. Reproduction issues in anorexia nervosa. Expert Rev Obstet Gynecol 2011;6:403-14.

40. Munsch S, Herpertz S. Eating disorders associated with obesity and diabetes. Nervenarzt 2011;82:1125-32.

41. National Eating Disorders Collaboration Comorbidity; 2021. Available from: https://nedc.com.au/eating-disorders/eatingdisorders-explained/types/comorbidity/. [Last accessed on 01 Feb 2021].

42. Cavan J, Connan F. Eating disorders management. Clin Pharm 2010. p. 330-3. Available from: https://www.pharmaceuticaljournal.com/files/rps-pjonline/pdf/cp201010_eating management-330.pdf. [Last accessed on 01 Feb 2021].

43. Fleming J, Szmukler GI. Attitubes of medical professionals towards patients with eating disorders. Australian New Zealan J Psychiatry 2009;26:436-43. 